\title{
Online Inspection of Weld Quality in Ultrasonic Welding of Carbon Fiber/Polyamide 66 without Energy Directors
}

\author{
A method of inspection was developed based on \\ target horn displacement and duration
}

BY Q. ZHI, Y.-H. GAO, L. LU, Z.-X. LIU, AND P.-C. WANG

\begin{abstract}
In this study, a method of inspecting the weld quality (i.e., static strength) in ultrasonic welding of 4-mm- (0.16-in.-) thick carbon fiber/polyamide $66\left(\mathrm{C}_{f}\right)$ PA66) composite with $30 \mathrm{wt}$ \% fiber without energy directors was investigated. The transient horn displacements and dissipated powers were recorded to correlate with the weld quality. It was found that the transient horn displacement of the joint during the ultrasonic welding process displayed four distinct stages: $\mathrm{C}_{\mathrm{f}}$ /PA66 expansion phase (stage I), unsteady melting phase (stage II), equilibrium phase of the materials melting and melt outflow (stage III), and the material cooling down phase (stage IV). The weld quality was closely related to the horn displacement and duration in stage III of the ultrasonic welding process. Target horn displacement and duration in stage III were determined by desired static strengths of the welded 4-mm- (0.16-in.-) thick $C_{f} /$ PA66 composite. The horn displacements and durations of the welds in stage III were recorded and the measurements were compared with the target values during welding. A quality weld was determined by judging whether the measured values of horn displacement and duration in stage III were within the tolerance range of the target values. Consequently, an online inspection method to evaluate the weld quality was developed based on target horn displacement and duration.
\end{abstract}

\section{KEYWORDS}

- Ultrasonic Welding • Carbon Fiber/Polyamide $66 \cdot$ Weld Quality

- Online Inspection

\section{Introduction}

Automobile exhaust emission has drawn wide public concern and one possible solution to this issue is reducing the weight of vehicles (Refs. 1-4). Lightweight materials, such as advanced polyamide composites reinforced by primary carbon fibers, are being increasingly used in automotive and aerospace applications due to their good mechanical properties and low density (Refs. 1, 5, 6). To obtain complex components, which often consist of small parts, joining the polyamide parts becomes a primary priority (Refs. 7-10). Among all the joining techniques available, ultrasonic welding is one of the most promising methods because it is fast, energy efficient, potentially suitable for mass production, and offers sound cosmetic quality (Refs. 11-14).

The key feature of ultrasonic welding is that the ultrasonic vibrations produce the intermolecular diffusion and the entanglement of the molecular chain in the molten state on the interfaces of the welded polymer due to the intermolecular friction within the thermoplastics (Refs. 11-14). To increase the welding speed and weld quality, the energy director is usually recommended to direct and focus the ultrasonic weld energy to a smaller contact area (Refs. 15, 16). However, due to the difficulty in locating the energy directors in the lapped workpieces with a robot, ultrasonic welding of the workpieces without energy directors was assessed. To facilitate the use of the ultrasonic welded polymeric composites for lighter, stronger, and more cost-effective vehicle structures, manufacturing guidelines for composite structures are required. The development of these guidelines requires not only detailed understanding of the ultrasonic welding process but also the quality monitoring and controlling of the ultrasonic welded joints.

To inspect the weld quality, various methods (e.g., destructive such as the chisel test) or nondestructive testing (e.g., ultrasonic technique (Ref. 15)) have been applied to assess the weld quality. Although the chisel test has some advantages, such as its relative ease of use, low cost, and usability on 


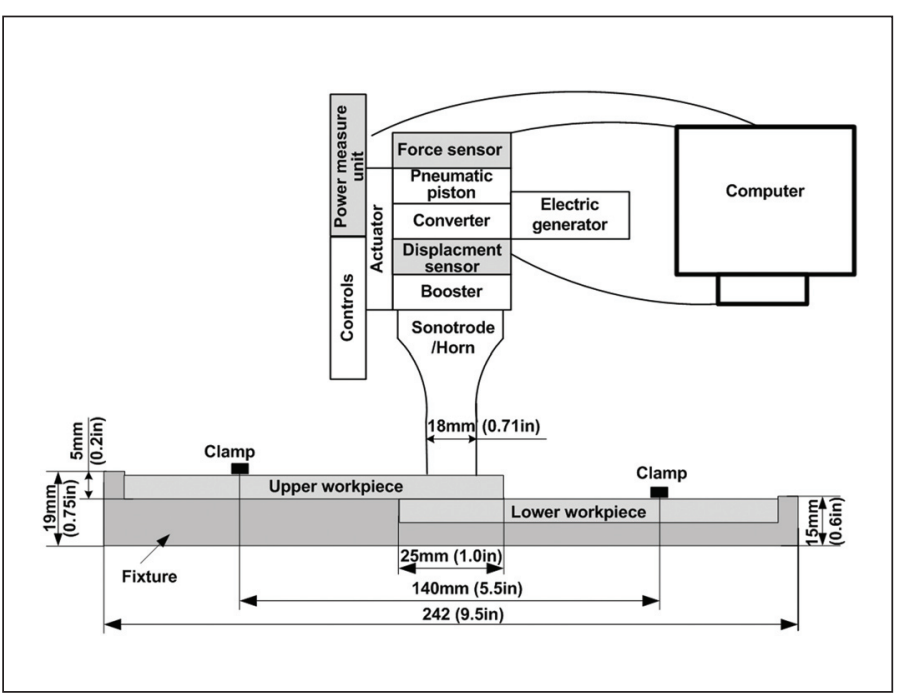

Fig. 1 - Schematic for ultrasonic welding of injection molded carbon fiber/polyamide 66 composite.

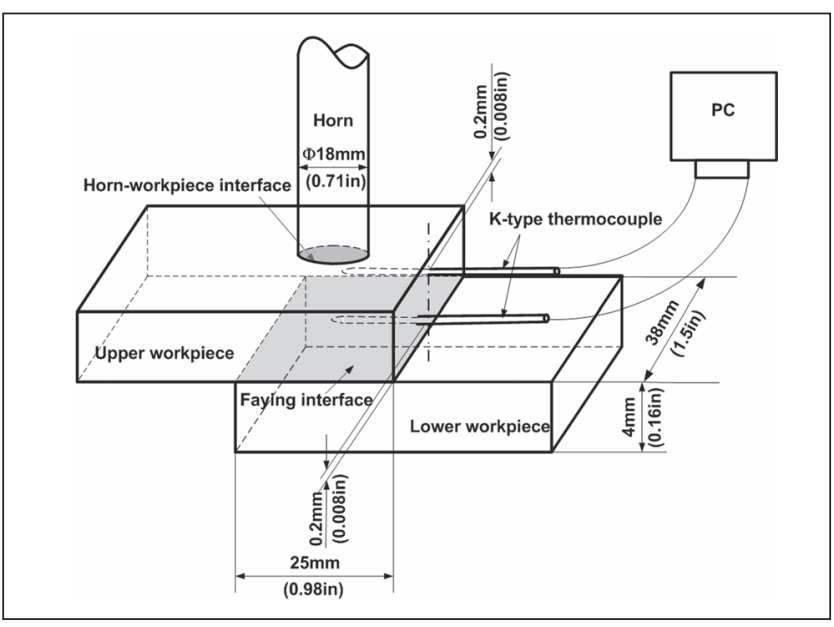

Fig. 2 - Sketch of the temperature measurements during the ultrasonic welding of injection molded 4-mm- (0.16-in.-) thick lapped carbon fiber/polyamide 66 composite without energy directors. the shop floor, the tests are qualitative and subjective. The ultrasonic method often requires a relatively long cycle time and couplant gel. It is often used offline for quality inspection of the welded workpieces. Therefore, it is imperative to develop an online nondestructive inspection method to evaluate the quality of the ultrasonic welded thermoplastic composites.

An extensive literature review revealed that few studies have reported on online nondestructive inspection for ultrasonic welds. Tolunay (Ref. 17), Stokes (Ref. 18), and Wijk (Ref. 19) previously found signals (i.e., ultrasonic wave and process signatures) could indirectly reflect the weld quality. Bates et al. (Ref. 20) studied the effect of imperfect mating parts on the vibration welding of a polyamide 66 compound and found the part quality was correlated to the meltdown profile. Villegas et al. (Refs. 21, 22) discovered that the quality of the ultrasonic welded lap joints of CF/PEI with a flat energy director was related to the process signatures (e.g., horn displacement and dissipated power of the process). However, the quantitative correlation between the joint strength and process signatures was not reported.

The present study was undertaken to develop a method for inspecting ongoing welding operations as a sequence of ultrasonic welded carbon fiber/polyamide 66 composite joints with 30 wt- $\%$ fiber without energy directors being formed. We first focused our attention on conducting the tests to understand the effect of process variables on the joint strength. Then, microstructures and weld formation mechanism of the ultrasonic welded joints were analyzed and the correlation between the joint strength and process signatures was investigated. Finally, the application of this method for weld quality inspection was discussed.

\section{Experimental Procedure}

\section{Materials}

Commercial polyamide 66 and carbon fiber (24 K, T300 type, Toray Carbon Magic Co. Ltd.) with a length of 2 $\mathrm{mm}$ (0.08 in.) were used. The fibers were first cleaned with a concentrated solution of nitric acid and then surface pretreated using $8 \%$ diglycidyl ether of bisphenol solution in acetone. Both polyamide 66 and pretreated carbon fibers were dried at $80^{\circ} \mathrm{C}$ in a vacuum condition for $3 \mathrm{~h}$ before being used to fabricate 30 wt- $\%$ carbon fiber/ polyamide 66 composite.

A twin-screw extruder with two separate inlets was used to mold 30 wt-\% carbon fiber/polyamide 66 composite. Polyamide 66 was added to the first hopper, and carbon fibers were added to the second hopper.

Polyamide 66 was also fully melted before carbon fibers were added to minimize the fracture of carbon fiber during compounding. The processing tem- perature was $270^{\circ}-280^{\circ} \mathrm{C}$

$\left(518^{\circ} \sim 536^{\circ} \mathrm{F}\right)$, and the screw speed was 180 roations per min (rpm). After fully mixing polyamide 66 with carbon fibers in a twin-screw extruder, the carbon fiber/polyamide 66 composite was processed into the pellets with a length of $2 \mathrm{~mm}$ (0.08 in.). The pellet was then fed into the injection extruder to mold into coupons with dimensions of $132 \times 38 \times 4 \mathrm{~mm}(5.2 \times 1.5 \times$ 0.16 in.). All coupons were stored in an ambient laboratory environment $\left(20^{\circ} \mathrm{C}\left(68^{\circ} \mathrm{F}\right)\right.$ and $50 \%$ R.H.) and dried in a vacuum oven at $80^{\circ} \mathrm{C}\left(176^{\circ} \mathrm{F}\right)$ for $48 \mathrm{~h}$ before welding to completely remove moisture in the specimen. The injection molded carbon fiber/ polyamide 66 composite exhibited a tensile strength of $99.2 \pm 3 \mathrm{MPa}$ ((1.4 $\pm 0.4) \times 104 \mathrm{lb} /$ in. $\left.^{2}\right)$ and an elastic modulus of $8936 \pm 3 \mathrm{MPa}((1.3 \pm 0.6)$ $\times 106 \mathrm{lb} /$ in. $\left.^{2}\right)$, respectively.

\section{Ultrasonic Welding Process}

The ultrasonic welding process was performed using a KZH-2026 multifunction UW machine (Weihai Kaizheng Ultrasonic Technologies Co. Ltd., China) with a nominal power of $2.6 \mathrm{~kW}$, nominal frequency of $20 \mathrm{kHz}$, and nominal amplitude of $25 \mu \mathrm{m}$ (9.8 $\times 10^{4}$ in.). The machine was equipped with a data acquisition system that combined a horn pressure sensor, horn-displacement sensor, and a timer, which were integrated in the controller of the UW machine, as shown in Fig. 1. In addition, the horn 


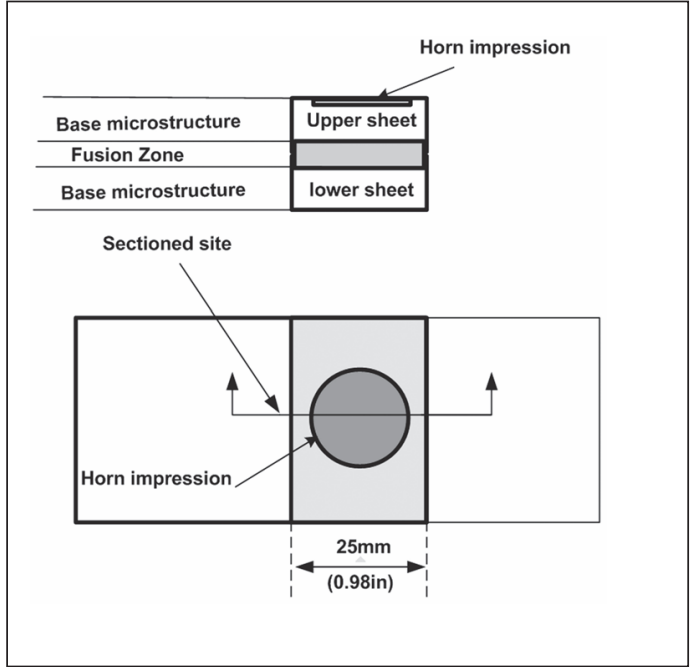

Fig. 3 - Schematic of a sample preparation for examining the microstructure of the ultrasonic welded 4-mm- (0.16-in.-) thick injection molded carbon fiber/polyamide 66 composite.

pressure, weld energy, and horn displacement were recorded online in a personal computer (PC) as a function of time by the data acquisition system. The final horn displacement, weld energy, weld time, horn pressure, hold time, and delay time were also displayed in the control panel during the UW process. To avoid coupon motion during welding, the coupons were held in place by using a fixture.

The machine had three modes: energy, time, and horn displacement. The value of weld energy, weld time, and horn displacement for the three modes, respectively, were preset to control the welding process. The workpieces were then welded using the nominal power of the machine. When the weld energy, weld time, or horn displacement reached the preset values for the selected weld mode, the ultrasonic wave oscillation was stopped. Therefore, weld quality was controlled by the preset values in each selected welding mode. When time mode was selected, the values of the delay time, weld force, hold time, and ultrasonic time were preset prior to welding. When the ultrasonic triggering was performed, the horn was pressed onto the workpieces for $2 \mathrm{~s}$, and then it ultrasonically vibrated until the preset time was reached. The welded workpieces were held for $3 \mathrm{~s}$ to solidify the molten material. All specimens were welded using a 7075 aluminum horn with a diameter of $18 \mathrm{~mm}$ (0.71 in.).

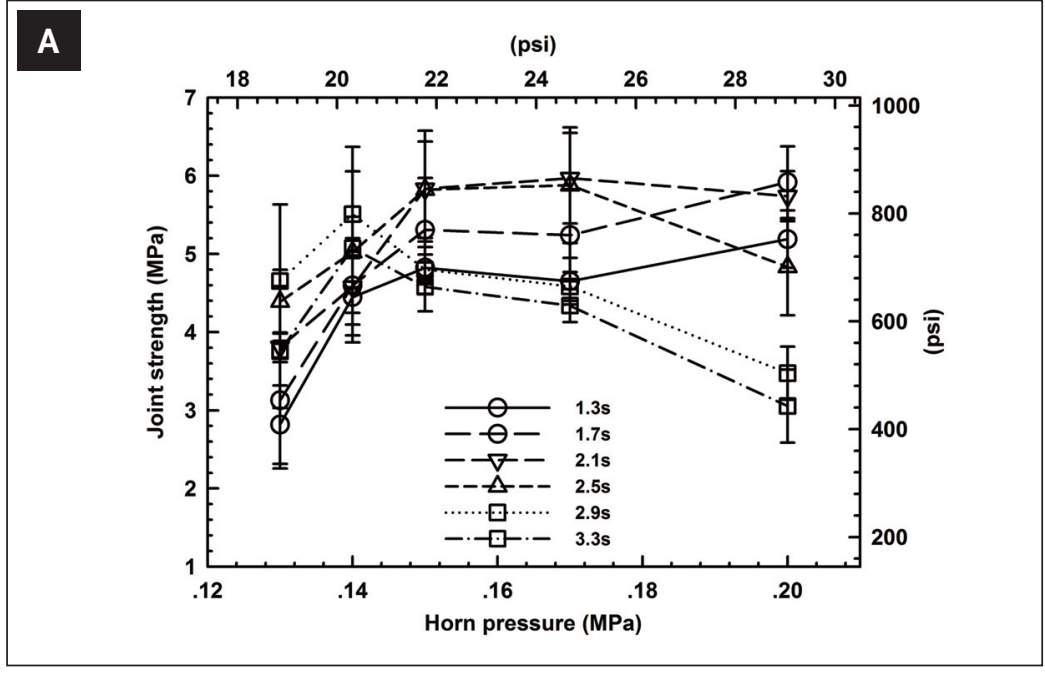

B

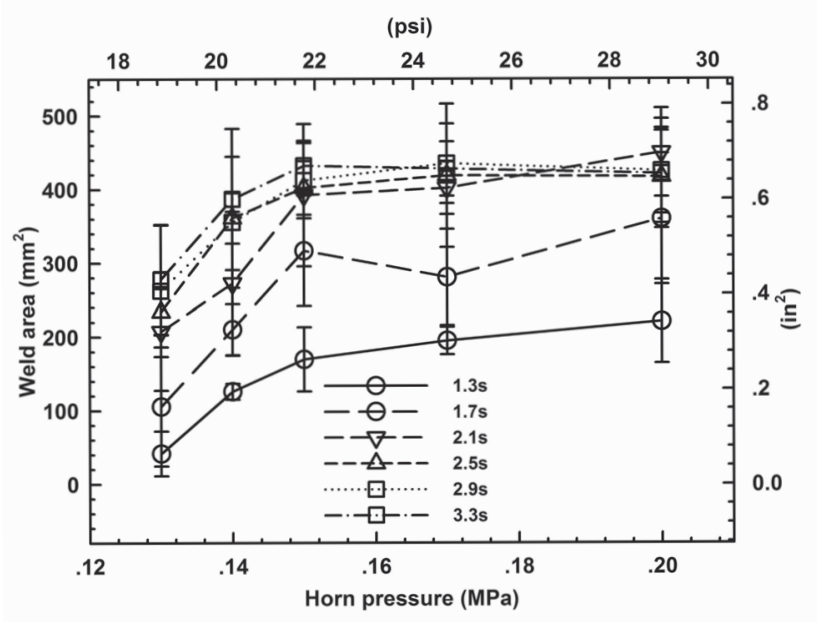

Fig. 4 - Influences of welding time and horn pressure on - A - static strength; B - weld area of the ultrasonic welded 4-mm- (0.16-in.-) thick lap carbon fiber/polyamide 66 composite with 30 wt-\% carbon fiber.

\section{Temperature Measurement}

To analyze the weld initiation and growth during ultrasonic welding, the temperature evolutions at the locations near the horn-workpiece interface and faying surface were measured. Figure 2 shows the experimental setup for temperature measurements. As shown, two small holes with a diameter of $1.0 \mathrm{~mm}$ (0.04 in.) and a depth of $12.5 \mathrm{~mm}$ (0.49 in.) were drilled at the side of the upper workpiece. Two holes were drilled at 0.2 $\mathrm{mm}$ (0.008 in.) from the top and bottom surfaces of the upper workpiece, respectively. Two K-type thermocouples were imbedded into the two small holes and secured with epoxy compound so that the thermocouples were secured. The temperature evolutions at these two locations were recorded as a func- tion of time by a data acquisition system during ultrasonic welding.

\section{Weld Microstructure}

To assess the characteristics of the weld microstructure of the ultrasonic welded joints, the specimens were prepared using the procedures shown in Fig. 3 for the tested joints. In Fig. 3, the joints were notched from the central position of the weld. Then, the prenotched specimens were immersed in liquid nitrogen for $10 \mathrm{~min}$. The embrittled specimens were broken off from the notched site; the broken specimens were sputter-coated with gold for $50 \mathrm{~s}$ to increase the conductivity, and the microstructures of the welds were examined with a scanning electron microscope (JSM6700F). 


\section{Quasi-Static Test}

Quasi-static tests were performed by loading each specimen to failure in an MTS 810 tensile tester according to ASTM D1002-2001. To minimize bending stresses inherent in the testing of single-lap weld specimens, filler plates were attached onto both ends of the specimen using a masking tape to accommodate the sample offset. Load vs. displacement results were obtained, as the specimens were loaded at a stroke rate of $2 \mathrm{~mm} / \mathrm{min}(0.08$ $\mathrm{in} . / \mathrm{min})$. The strength of the joint is defined as the ratio of the peak load to the overlap area of the weld $\left(950 \mathrm{~mm}^{2}\right.$ $\left(1.47\right.$ in. $\left.^{2}\right)$ ). Three replicates were performed, and the average joint strengths were reported.

\section{Results and Discussion}

\section{Quality of Ultrasonic Weld}

To understand the weld quality in ultrasonic welding of 4-mm-(0.16-in.-) thick lap carbon fiber/polyamide 66 composite with $30 \mathrm{wt}-\%$ fiber, extensive welding tests were performed. In setting up the welding machine to produce a series of uniform welds, initial values of suitable horn pressure, welding time, and clamping conditions were established for the welding horn and specific workpieces. The welding controller was programmed in an attempt to maintain these values so that the same welds are produced during extended manufacturing operations.

Figure 4A, B shows the effect of process variables on the weld strength and weld area for an ultrasonic welded 4-mm- (0.16-in.-) thick lap carbon fiber/polyamide 66 composite, respectively. As shown, significant scatter in the weld strength and weld area for the joints made under the same welding conditions was observed. Careful analyses of the results revealed that the scatter likely resulted from the variations in weld area. To validate this speculation, the failure modes of the tested joints made with a welding time of $2.1 \mathrm{~s}$ and a horn pressure of $0.15 \mathrm{MPa}(21.76$ $\mathrm{lb} /$ in. $^{2}$ ) were examined.

Figure $5 \mathrm{~A}, \mathrm{~B}$ presents an interfacial failure mode and a mixed mode of interfacial and workpiece fracture, respectively. Examination of the failure

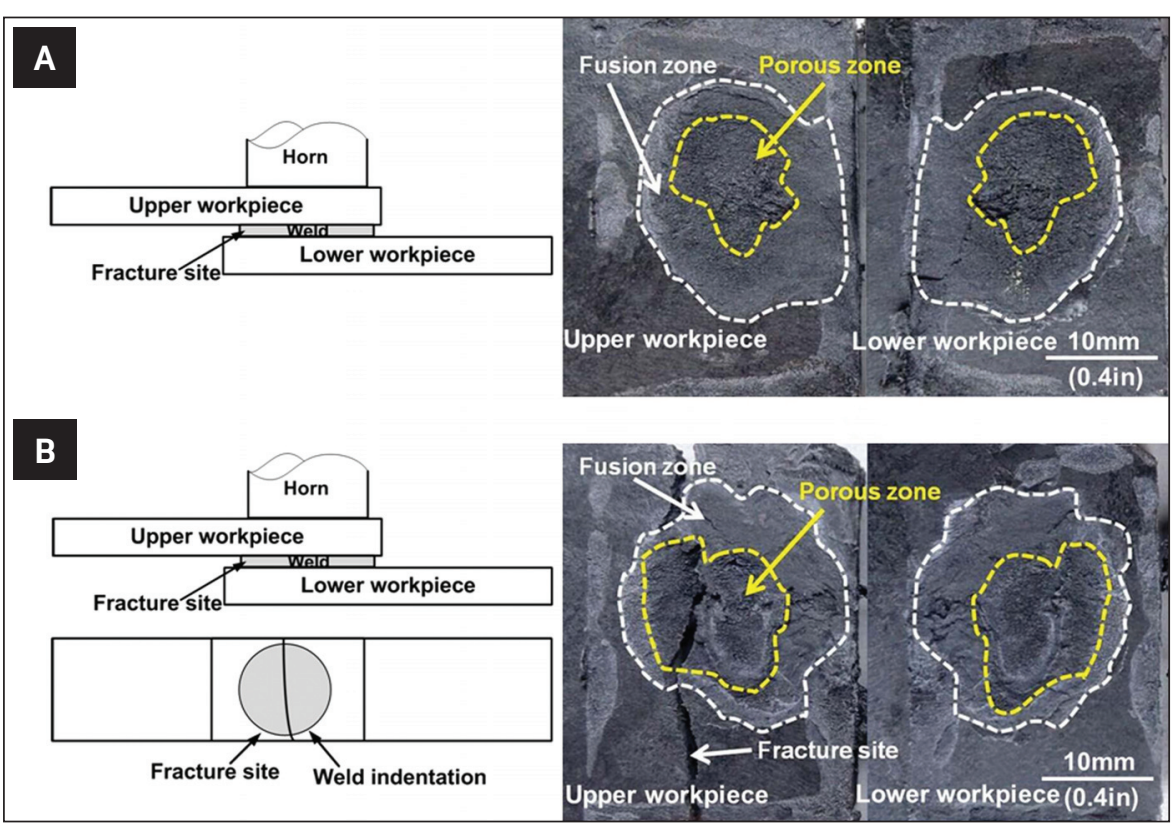

Fig. 5 - Failure modes for the ultrasonic welded 4-mm- (0.16-in.-) thick lap carbon fiber/polyamide 66 composite with 30 wt-\% carbon fiber and without an energy director fabricated with a welding time of $2.1 \mathrm{~s}$ and a horn pressure of $0.15 \mathrm{MPa}$ (21.76 lb/in.2): A - interfacial failure; B - mixed interfacial and workpiece fracture.

mode shown in Fig. 5A exhibited that the cracks initiated at the intersection of the weld and opening between the workpieces, and grew through the weld nugget. Ultimate failure was by overload of the remaining unseparated sections. A different failure mode, referring to Fig. 5B, revealed that the cracks initiated at the pores inside the weld, and then propagated through the thickness of the upper workpiece.

In combining Figs. 4 and 5, it can be seen the joints that failed with an interfacial failure mode had greater strength than the joints that failed with a mixed failure mode. Figure $6 \mathrm{~A}$, $\mathrm{B}$ showed the microstructures of the joints failed with interfacial and mixed fracture modes, respectively. As shown, significant pores were present at the porous zone for the joints with a mixed failure mode, as seen in Fig. 6B. The presence of pores in Fig. 6B was likely the culprit for the reduction in joint strength. Therefore, significant scatter in the joint strength, as in Fig. 4, likely resulted from the variations in weld quality. While the exact causes of pores are beyond the scope of this study, the implication of these results showed there is an urgent need to have an online system developed to monitor weld quality.

\section{Weld Growth Mechanism}

To develop the weld monitoring system, it is necessary to understand how the weld initiates and grows during the welding of 4-mm- (0.16-in.-) thick lap carbon fiber/polyamide 66 composite. From the results shown in the "Quality of Ultrasonic Weld" section, the optimal welding parameters for UW of $C_{f} / P A 66$ were a welding time of $2.1 \mathrm{~s}$ and a horn pressure of $0.15 \mathrm{MPa}\left(21.76 \mathrm{lb} / \mathrm{in} .{ }^{2}\right)$. Thus, transient temperature histories near the faying surface and horn-workpiece interface, as well as the transient horn displacement for the joints made with the optimal welding parameters, were recorded. The results are shown in Fig. 7. In addition, the transient horn displacement during welding was also recorded and shown in Fig. 7. As shown, the weld initiation and growth could be divided into four stages during the welding, and each stage is discussed next.

\section{Stage I}

In this stage, ultrasonic vibration began, and the friction between the horn-workpiece and workpiece-workpiece resulted in an increase in temperature at both interfaces. Small as- 

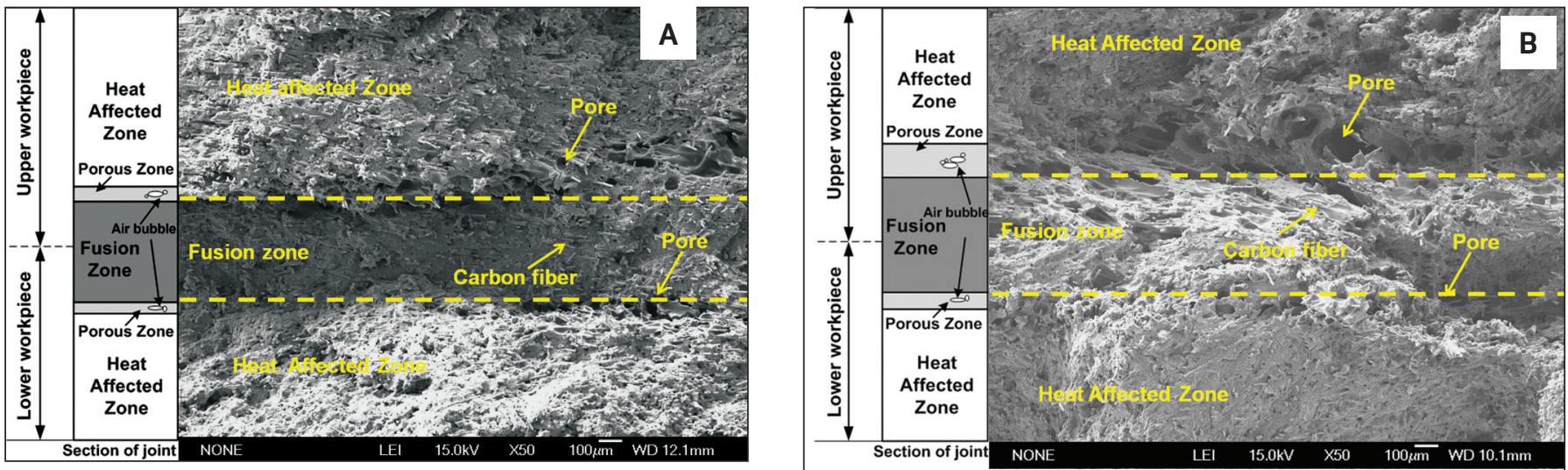

Fig. 6 - Microstructures of the ultrasonic welded 4-mm- (0.16-in.-) thick lapped carbon fiber/polyamide 66 composite with 30 wt-\% carbon fiber and without energy directors fabricated with a welding time of $2.1 \mathrm{~s}$ and a horn pressure of $0.15 \mathrm{MPa}$ (21.76 lb/in.2): microstructure of $-A-$ nominal; $B-$ discrepant weld.

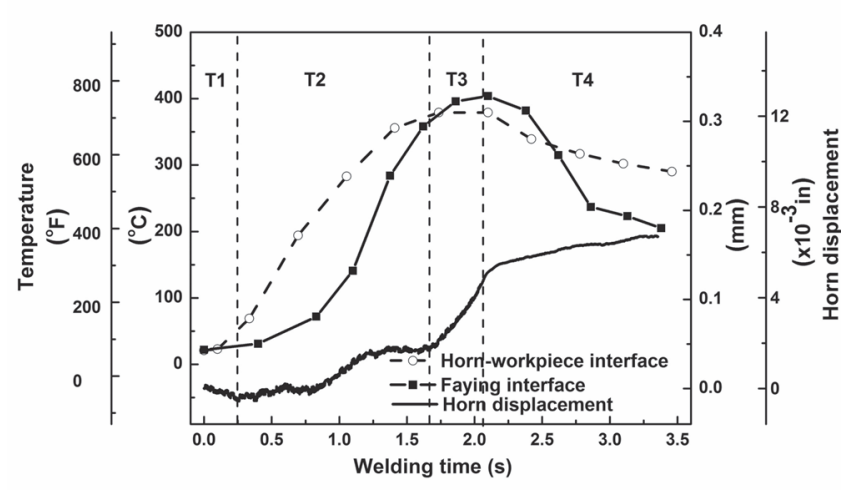

Fig. 7-Temperature-time histories near the horn-workpiece and faying surfaces as well as horn displacement for ultrasonic welding of 4-mm- (0.16-in.) thick lap carbon fiber/polyamide 66 composite with $30 \%$ mass fiber and without an energy director fabricated with a welding time of $2.1 \mathrm{~s}$ and a horn pressure of $0.15 \mathrm{MPa}\left(21.76 \mathrm{lb} / \mathrm{in}^{2}{ }^{2}\right)$.

perities were in contact at the faying surface, where high stresses were concentrated on these asperities, and consequently the temperature increased to $70^{\circ} \mathrm{C}\left(158^{\circ} \mathrm{F}\right)$ near the faying surface within $0.35 \mathrm{~s}$. As the welding continued, the temperature near the horn-workpiece interface barely increased after a welding time of $0.35 \mathrm{~s}$ and the horn displaced slightly upward primarily resulting from the expansion of the materials. Figure 8A, B shows the weld indentation and weld area with a welding time of $0.3 \mathrm{~s}$, respectively. As shown, little weld indentation and a small weld with an irregular shape were observed in stage I.

\section{Stage II}

In stage II, friction between interfaces and viscoelastic dissipation of the material resulted in an increased temperature at the interfaces. Referring to Fig. 7, the temperature near the faying surface virtually increased linear with the welding time and reached a peak temperature of $379^{\circ} \mathrm{C}$ $\left(714^{\circ} \mathrm{F}\right)$ at a welding time of $1.7 \mathrm{~s}$, which exceeded the melting point $\left(259^{\circ} \mathrm{C}\left(498^{\circ} \mathrm{F}\right)\right)$ of carbon fiber/ polyamide 66 composite. The melting at the faying surface began to grow and spread, and the corresponding horn displacement increased slowly. Due to the molten material serving as a "lubricating agent" (Ref. 23), the friction energy dissipated as the faying surface decreased, and consequently the melt rate of materials at the faying surface began to decrease. Although the raising temperature rate near the faying surface decreased, the temperature continuously increased to reach a stable $379^{\circ} \mathrm{C}\left(714^{\circ} \mathrm{F}\right)$.

Figure 9A to D shows the weld in- dentation and weld area for the welding time of $0.5,0.9,1.3$, and $1.7 \mathrm{~s}$, respectively, in stage II. As shown, the weld indentation and weld area grew with welding time, which resulted in a melted film forming at the faying surface, and the horn moved downward. Referring to Fig. 7, as the temperature increased near the faying surface, the temperature near the horn-workpiece increased as well. The temperature near the horn-workpiece interface reached about $360^{\circ} \mathrm{C}\left(680^{\circ} \mathrm{F}\right)$ with a welding time of $1.7 \mathrm{~s}$, which resulted in a weld indentation of about $0.05 \mathrm{~mm}(0.002$ in.) on the upper workpiece.

\section{Stage III}

In stage III, referring to Fig. 7, as the temperature near the faying surface stabilized, the temperature near the horn-workpiece interface increased with time. Figure 10A, B shows the weld indentation and weld area with a welding time of $2.1 \mathrm{~s}$, respectively. As shown, as the horn indented into the upper workpiece, a melt film formed, and some molten materials were flashed out of the faying surface. As a result, a sharp increase in horn displacement was observed in stage III. Under this condition, the melt rate of materials was in equilibrium with the spread rate of the melt (Ref. 24).

It is noted from Fig. 7 that although the temperature near the horn-workpiece interface was lower than that of the region near the faying surface at the beginning of the ultrasonic welding process, it reached about 


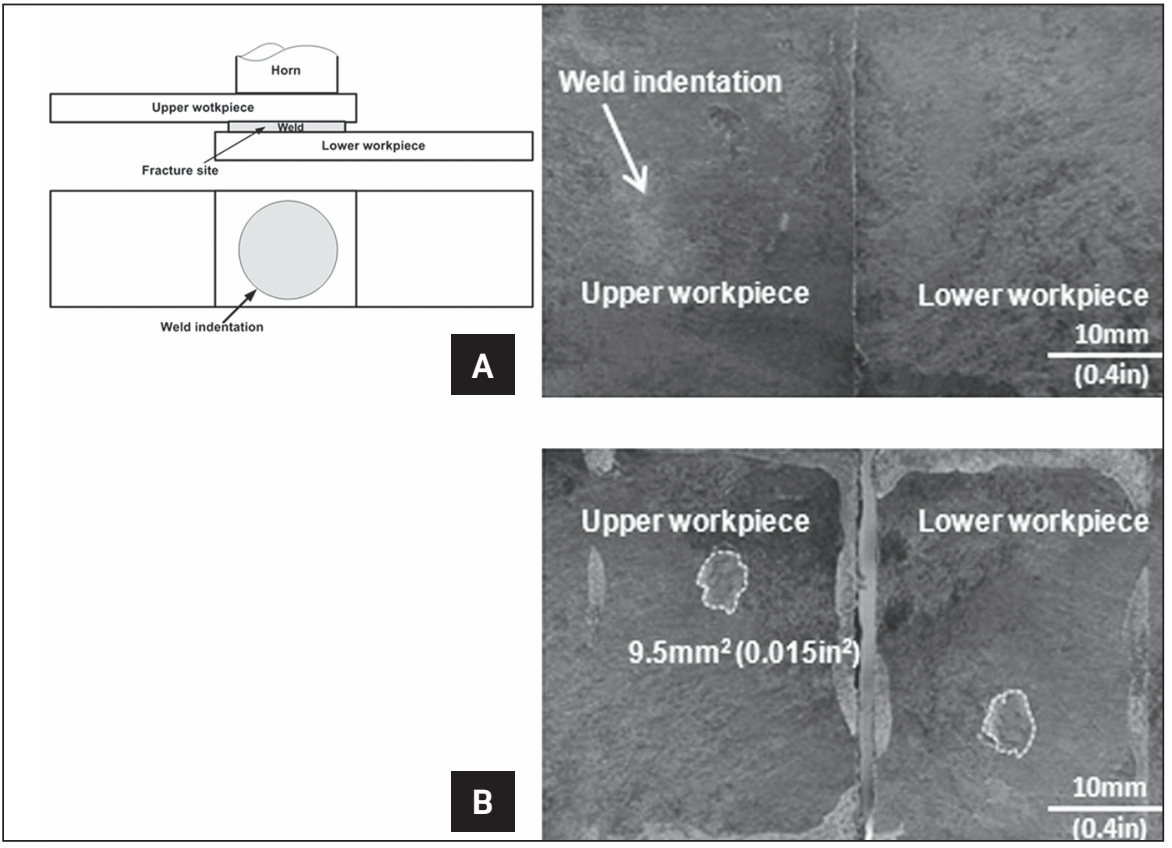

Fig. $8-A-$ Weld indentation; B - weld size at the faying surface of the ultrasonic welded 4-mm- (0.16-in.-) thick carbon fiber/polyamide 66 composite with 30 wt-\% fiber and without an energy director fabricated with a welding time of $0.3 \mathrm{~s}$ and a horn pressure of $0.15 \mathrm{MPa}\left(21.76 \mathrm{lb} / \mathrm{in}^{2}{ }^{2}\right.$ ) (stage I).

$404^{\circ} \mathrm{C}\left(759^{\circ} \mathrm{F}\right)$ in stage III. These results inferred that as the energy dissipated and the faying surface decreased, more energy was dissipated at the horn-workpiece interface, which was mainly because the upper workpiece softened from dissipated heat and made the ultrasonic vibration difficult to transmit into the faying interface. The temperatures near the faying and horn-workpiece interfaces were much higher than the melting point $\left(259^{\circ} \mathrm{C}\left(498^{\circ} \mathrm{F}\right)\right)$ of carbon fiber/polyamide 66 composite, which likely degraded polyamide 66 and resulted in volatile gases observed at the porous zone (Ref. 25).

\section{Stage IV}

Ultrasonic vibration was stopped and the melt began to solidify in stage IV. Referring to Fig. 7, the temperatures near the faying and horn-workpiece interfaces decreased with time as the horn moved slightly downward resulting from the material contracting. From the above analyses, we can conclude that the weld initiation and growth mainly depended on the energy consumed by the materials at the faying surface.

\section{Correlation Between Horn Displacement and Dissipated Power}

From the analyses above, it was noted that the energy dissipated at the faying surface was related to the weld area. In this section, the correlation between the weld area and energy dissipation, and how the dissipated power relates to the horn displacement that can reflect the weld growth, are examined.

It is well known that the heat rate of the faying surface during the ultrasonic welding process is determined by the viscoelastic dissipation and friction between two workpieces, and thus by the dissipated power (Refs. 11, $19,26,27)$. The lumped parameter model for the simulation of the ultrasonic welding of thermoplastics proposed by Benatar et al. demonstrated that the instantaneous dissipated power (Ws) during ultrasonic welding was closely related to the impendence of horn-workpieces interface, faying surface, and workpiece-anvil interface (Ref. 12).

$$
\begin{aligned}
& P_{1}=2 \pi f E^{\prime \prime}\left(A_{0} / L_{1}\right)^{2}\left(0.5-Z_{2}\right. \\
& \left.\cos \phi_{2}+0.5 Z^{2}{ }_{2}\right)
\end{aligned}
$$

$$
\begin{aligned}
& P_{2}=2 \pi \mathrm{fE} "\left(\mathrm{~A}_{0} / \mathrm{L}_{2}\right)^{2}\left[0 . 5 \left(\mathrm{Z}^{2}{ }_{2}\right.\right. \\
& \left.\left.+\mathrm{Z}^{2}\right)+\mathrm{Z}_{2} \mathrm{Z}_{3} \cos \left(\phi_{2}-\phi_{3}\right)\right] \\
& P_{3}=2 \pi \mathrm{fE} "\left(\mathrm{~A}_{0} / \mathrm{L}_{3}\right)^{2} \mathrm{Z}_{3}^{2} / 2 \\
& W_{\mathrm{s}}=P_{1}+P_{2}+P_{3}
\end{aligned}
$$

where $P_{1}, P_{2}$, and $P_{3}$ are the instantaneous dissipated power for the hornworkpiece, workpiece-workpiece, and workpiece-anvil interfaces, respectively. $E^{\prime \prime}$ is the loss modulus; $f$ is the vibration frequency; $\mathrm{A}_{0}$ is the amplitude of vibration; $L$ is the contact length of the faying surface; $Z_{2}$ and $Z_{3}$ are the impedances of the faying surface and workpiece-anvil interface, respectively; and $\phi_{2}$ and $\phi_{3}$ are the phase angles of the vibration on the faying surface and workpiece-anvil interface, respectively. $W_{s}$ is the total energy dissipated during the ultrasonic welding process. Furthermore, experiments and simulation done by Benatar et al. (Ref. 12) and Villegas (Refs. 21, 22) showed that while the melting of asperities and energy directors at the faying surface caused an abrupt increase in the impedance of the faying surface $\left(\mathrm{Z}_{2}\right)$, a continuous decrease in dissipated power was observed. Therefore, similar observations were drawn that there was a connection among the ultrasonic vibration phase, dissipated power, and horn displacement.

To examine if the horn displacement relates to the dissipated power, the dissipated power and horn displacement of ultrasonic welding of 4mm- (0.16-in.-) thick carbon fiber/ polyamide 66 composite made with a welding time of $2.1 \mathrm{~s}$ under a horn pressure of $0.15 \mathrm{MPa}\left(21.76 \mathrm{lb} / \mathrm{in}^{2}{ }^{2}\right)$ were measured. Figure $11 \mathrm{~A}, \mathrm{~B}$ shows the results for the joints with the strengths of $6.1\left(884.7 \mathrm{lb} / \mathrm{in} .^{2}\right)$ and 4.7 MPa $\left(681.6 \mathrm{lb} /\right.$ in. $\left.^{2}\right)$, respectively. Referring to Fig. 11, the dissipated power in stage I linearly increased as the friction/viscoelastic dissipation occurred between the horn-workpiece and faying surface. Because of heating, the workpieces expanded, and consequently led to the horn moving upward. As the welding continued, more asperities at the faying surface melted in stage II, and the dissipated power reached a maximum value. This is followed by all asperities melting at the faying surface, and a steady melt film was formed in 

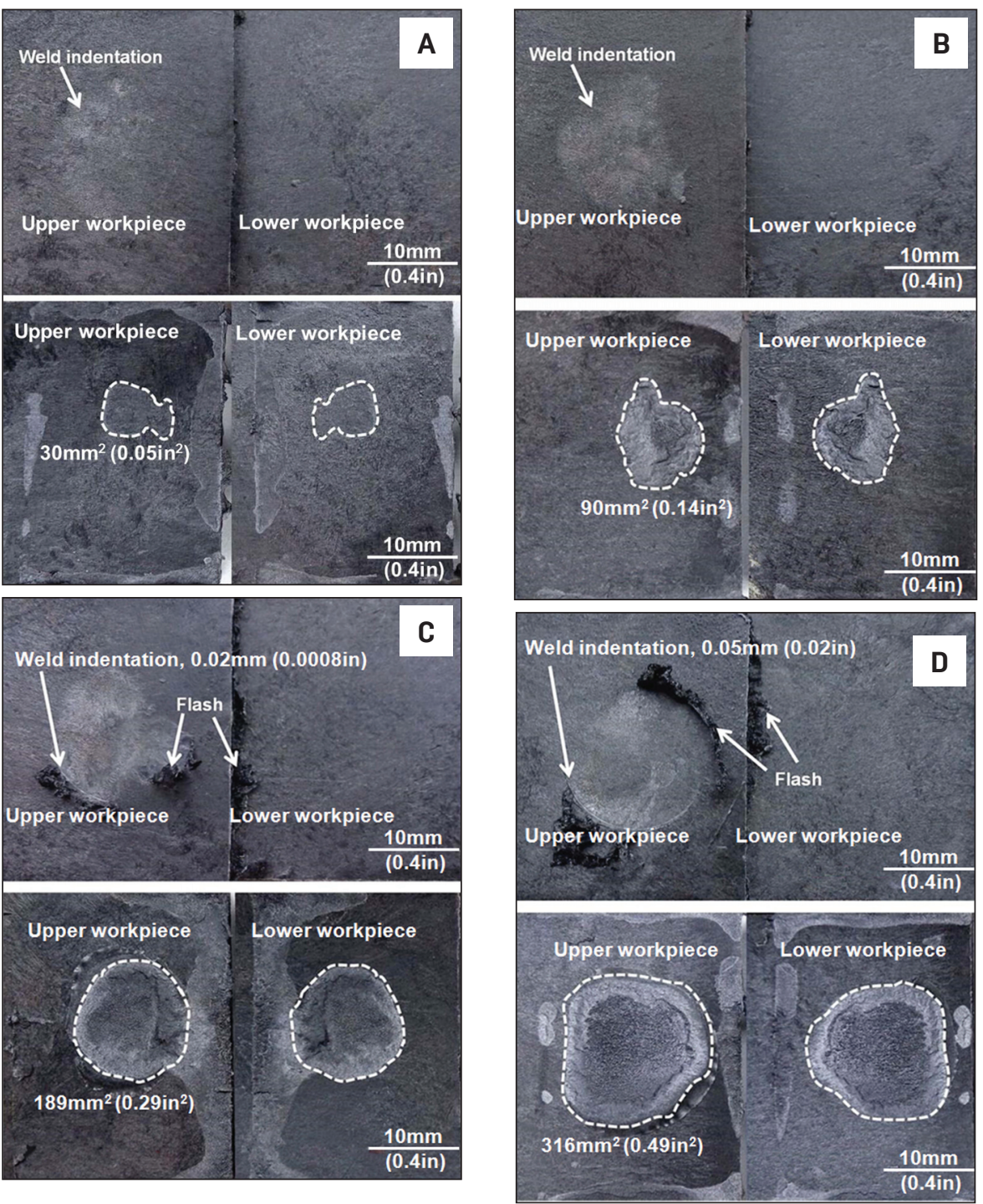

Fig. 9-Effect of welding time on the weld indentation and weld formation at the faying surface of the ultrasonic welded 4-mm- (0.16-in.-) thick carbon fiber/ polyamide 66 composite with $30 \mathrm{wt}-\%$ fiber and without an energy director fabricated with a horn pressure of $0.15 \mathrm{MPa}\left(21.76 \mathrm{lb} / \mathrm{in}^{2}{ }^{2}\right): \mathrm{A}-0.5 \mathrm{~s} ; \mathrm{B}-0.9 \mathrm{~s} ; \mathrm{C}-1.3 \mathrm{~s}$; $D-1.7$ s (stage II).

stage III. As the melting and spreading rates of material at the faying surface were in equilibrium, less vibration energy was required to melt the material at the faying surface to compensate the spread melt (Ref.

21). The horn displacement increased and dissipated power decreased with time until the ultrasonic vibration was stopped due to the formation of the melt at the faying surface. These results suggest the horn displacement and dissipated power were closely related.

Careful examinations of the results shown in Fig. 11 indicated the joint with a strength of $6.1 \mathrm{MPa}$ (884.7 $\mathrm{lb} /$ in. $^{2}$ ) had a greater increase in horn displacement and duration than that of the joint with a strength of $4.7 \mathrm{MPa}$ $\left(681.6 \mathrm{lb} /\right.$ in. $\left.^{2}\right)$ in stage III. Similar results were observed for the joints made with other welding variables. These results imply that the horn displacement and duration in stage III may be a good indicator of the quality in ultrasonic welding of carbon fiber/polyamide 66 composite.

\section{Extraction Horn Displacement and Duration of Stage III in Ultrasonic Welding}

As shown above, the changes of the horn displacement and duration in stage III play an important role in determining the joint strength. In this section, the extraction of the changes of horn displacement and duration in stage III during ultrasonic welding is studied. Figure 12 shows the horn displacement and partial dissipated power (2000 to $2060 \mathrm{~W}$ ) of Fig. 11A. Referring to Fig. 12, the change of the horn displacement $\left(\Delta D_{\mathrm{T} 3}\right)$ in stage III can be determined from the duration $\left(\Delta t_{T 3}\right)$ that is determined by the change of dissipated power. As shown in Fig. 12, the melting of asperities with various heights at the faying surface resulted in a fluctuation series of dissipated power in stage II. A melt film formed and the dissipated power dropped dramatically in stage III. Therefore, the sharp drop in dissipated power was an indicator of the starting time of stage III. The duration in stage III $\left(\Delta t_{T 3}\right)$ was determined from the sharp drop in dissipated power to the end of the vibration, referring to Fig. 13. Therefore, the change of horn displacement $\left(\Delta D_{T 3}\right)$ was determined as the duration where the dissipated power started to decrease in stage III until the end of vibration. The combination of the duration $\left(\Delta t_{T 3}\right)$ and change of displacement $\left(\Delta D_{T 3}\right)$ in stage III were then used to correlate the strength of ultrasonic welded carbon fiber/polyamide 66 composite.

\section{Correlation between Horn Displacement and Duration in Stage III and Joint Strength}

Once the method of inspecting the weld quality was proposed, it was necessary to validate this approach. Ultrasonic welding of carbon fiber/ polyamide 66 composite with $30 \%$ mass fiber was performed with a welding time of $2.1 \mathrm{~s}$ and a horn pressure of $0.15 \mathrm{MPa}$ (21.76 $\mathrm{lb} / \mathrm{in}^{2}{ }^{2}$. The horn displacement and dissipated power histories were recorded, and the changes in horn displacement and duration in stage III for each test were measured using the aforementioned method, referring to Fig. 12. Figure 13 presents the correlation between the joint strength and combination of duration $\left(\Delta t_{T 3}\right)$ and change of displacement $\left(\Delta D_{T 3}\right)$ in stage III. As shown, a grey zone that defines the joints with acceptable strength $(>5.5 \mathrm{MPa}$ (797.7 

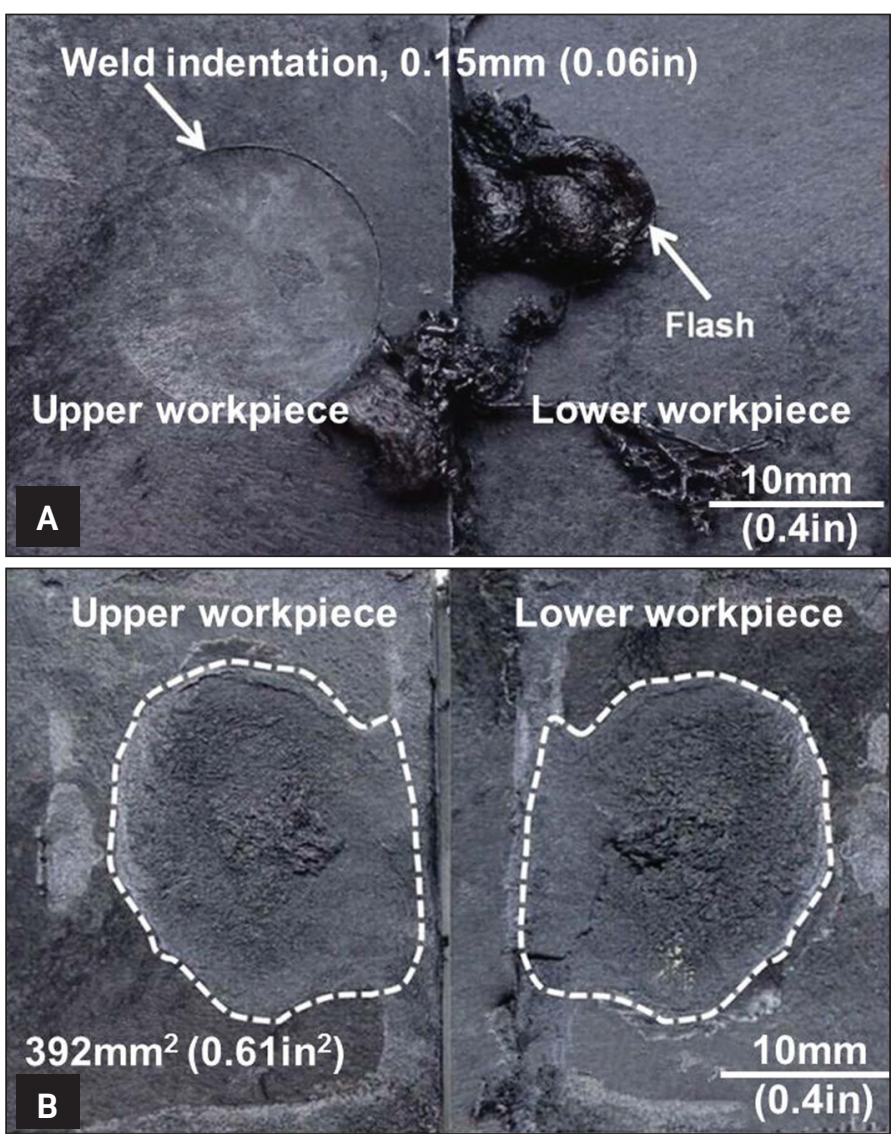

Fig. $10-A-$ Weld indentation; $B-$ weld at the faying surface of the ultrasonic welded 4-mm- (0.16-in.-) thick carbon fiber/polyamide 66 composite with 30 wt-\% fiber at a welding time of $2.1 \mathrm{~s}$ and a horn pressure of $0.15 \mathrm{MPa}\left(21.76 \mathrm{lb} / \mathrm{in}^{2}{ }^{2}\right)$ (stage III).
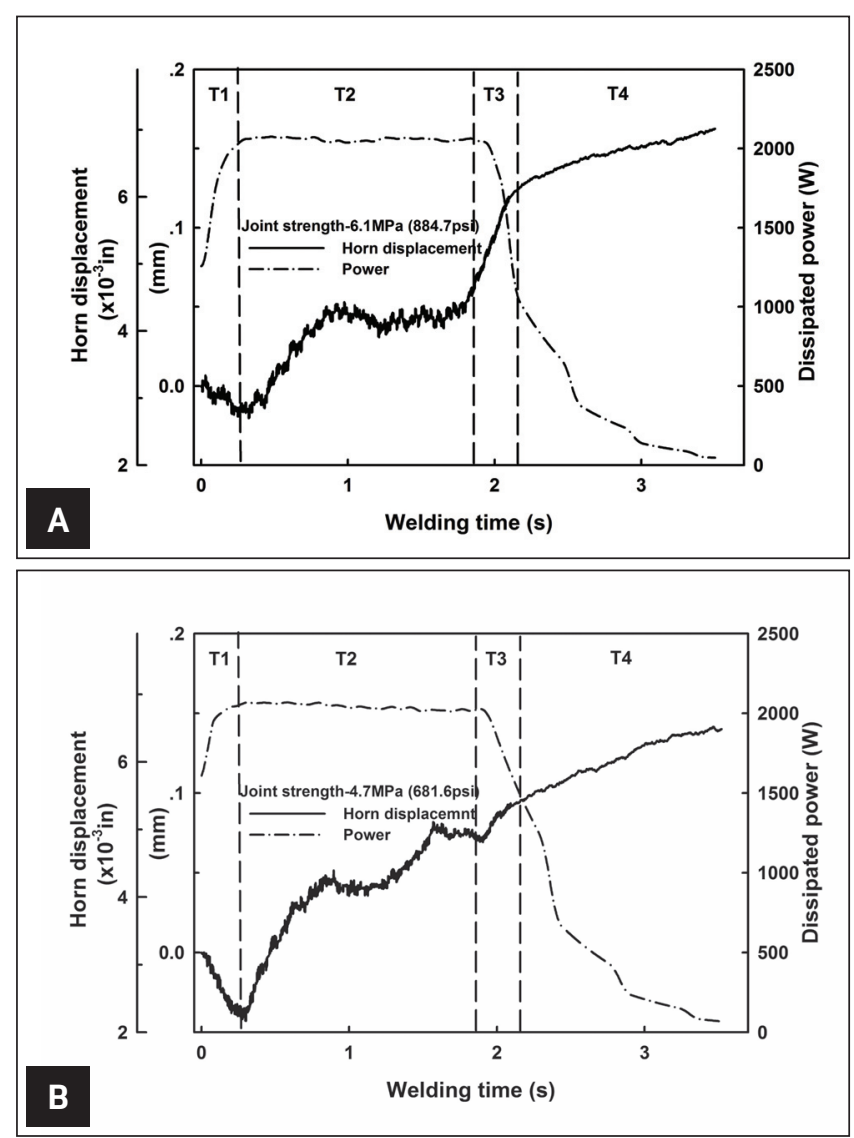

Fig. 11 - Horn displacement and dissipated power curves for the ultrasonic welded carbon fiber/polyamide $66 \mathrm{com}$ posite joints fabricated with a welding time of $2.1 \mathrm{~s}$ under $0.15 \mathrm{MPa}\left(21.76 \mathrm{lb} / \mathrm{in}^{2}{ }^{2}\right.$ ) and with strengths of $-\mathrm{A}-6.1 \mathrm{MPa}$ (884.7 psi); $B-4.7 \mathrm{MPa}\left(681.6 \mathrm{lb} / \mathrm{in}^{2}{ }^{2}\right.$ ). lb/in. $\left.{ }^{2}\right)$ ) was determined. These results suggest that if the duration and change of horn displacement $\left(\Delta D_{T 3}\right)$

in stage III of the ultrasonic welded joint fall in the range of the grey area, the joint with desired strength can be obtained.

Further analyzing the results shown in Fig. 13 revealed that to obtain a sound weld, the duration $\left(\Delta t_{\mathrm{T} 3}\right)$ and change of horn displacement $\left(\Delta D_{T 3}\right)$ in stage III must be kept in a proper range. The welds with small horn displacement $\left(\Delta D_{T 3}\right)$ had a thin film thickness, and consequently had a weak strength. On the other hand, the welds having long duration $\left(\Delta t_{T 3}\right)$ and a large change in horn displacement $\left(\Delta D_{T 3}\right)$ had a thick fusion zone with significant pores there. Both had a negative impact on the joint strength. Therefore, the key to producing a quality weld is to control the duration $\left(\Delta t_{\mathrm{T} 3}\right)$ and horn displacement $\left(\Delta D_{T 3}\right)$ in proper range for ultrasonic welding of carbon fiber/polyamide 66 composite. Referring to Fig. 13, to obtain the sound weld, the duration and change of horn displacement were in the ranges of 0.25 to $0.35 \mathrm{~s}$ and 0.04 (0.0016 in.) to $0.1 \mathrm{~mm}$ (0.004 in.), respectively, for ultrasonic welding of 4mm- (0.16-in.-) thick lap carbon fiber/ polyamide 66 composite.

\section{Application and Prospect of Horn Displacement for Weld Quality Inspection}

The aforementioned test results demonstrated that the correlation of the weld strength and horn displacement and duration in stage III of ultrasonic welding could be used to nondestructively assess the weld quality online. Target values for the horn displacement and duration in producing a sound weld are determined for the workpieces. During welding operation, the horn displacement and duration during the weld growth in stage III are continually taken and analyzed, and the results were compared with the target displacement and duration values. While the measured values are within a tolerance range of the target values, welding is continued using the preset parameters. When the measured horn displacement and duration fall outside the target range, either the fault alarm is flagged or welding parameters can be adjusted to correct the displacement and duration and, thereafter, welding is continued. Consequently, the horn displacement method would permit easy and efficient production of a series of substantially sound welds without interruption of the welding operation. Checking the horn displacement online is done without stopping the welding process.

\section{Conclusions}

1. The weld initiation and growth in ultrasonic welding of 4-mm- (0.16-in.-) thick lap carbon fiber/polyamide 66 


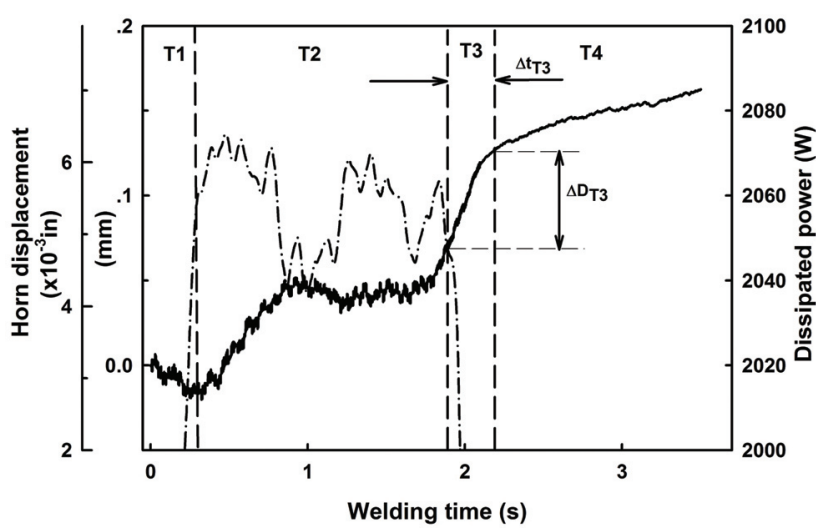

Fig. 12 - Method to extract the horn displacement $\left(\Delta D_{\text {т⿱ }}\right)$ and welding time $\left(\Delta \mathrm{t}_{T_{3}}\right)$ in stage III in ultrasonic welding of carbon fiber/polyamide 66 composite with 30 wt-\% fiber under a welding time of $2.1 \mathrm{~s}$ and a horn pressure of $0.15 \mathrm{MPa}\left(21.76 \mathrm{lb} / \mathrm{in}^{2}{ }^{2}\right)$.

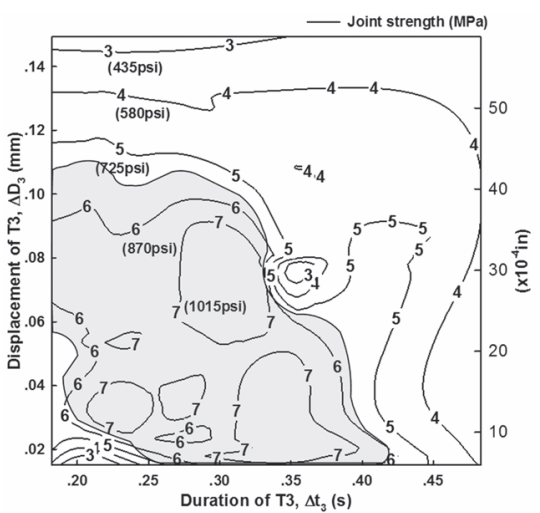

Fig. 13 - Correlation between the duration $\left(\Delta \mathrm{t}_{\mathrm{T} 3}\right)$ horn displacement $\left(\Delta \mathrm{D}_{\mathrm{T}_{3}}\right)$ in stage III and strengths for the ultrasonic welded 4-mm- (0.16-in.-) thick lap carbon fiber/polyamide 66 composite with 30 wt-\% fiber. composite with $30 \mathrm{wt}$-\% fiber without an energy director was composed of four stages, namely, the $\mathrm{C}_{\mathrm{f}}$ /PA66 expansion phase (stage I), the unsteady melting phase (stage II), the equilibrium phase of the materials melting and the melt outflow (stage III), and the material cooling down phase (stage IV).

2. Under a given horn pressure, melt spread (i.e., weld area) was closely related to the horn displacement as well as duration in stage III of the welding process.

3. The criterion for producing quality welds was to keep the duration $\left(\Delta t_{T 3}\right)$ and horn displacement $\left(\Delta D_{\mathrm{T}}\right)$ in stage III in proper range for ultrasonic welding of 4-mm- (0.16-in.-) thick carbon fiber-reinforced polyamide 66 composite. Moreover, the target horn displacement and duration were determined by desired static strengths of the welded workpieces.

4. An online inspection method to evaluate the weld quality was developed. The horn displacement and duration of the weld in stage III during welding were recorded, and the measurements were compared with the target values. A quality weld was determined by judging whether the measured values of horn displacement and welding time were within the tolerance range of the target values.

\section{Acknowledgments}

The authors gratefully acknowledge the financial and technical support provided by GM Global Research and Development.

\section{References}

1. Elalem, A., and El-Bourawi, M. S. 2010. Reduction of automobile carbon dioxide emissions. International Journal of Material Forming 3(1): 663-666.

2. Van den Brink, R. M. M., and Van Wee, B. 2001. Why has car-fleet special fuel consumption not shown any decrease since 1990? Quantitative analysis of Dutch passenger car-fleet special fuel consumption. Transportation Research Part D 6(2): 75-93.

3. Duflou, J. R., De Moor, J., Verpoest, I., and Dewulf, W. 2009. Environmental impact analysis of composite use in car manufacturing. Manufacturing Technology 58(1): 9-12.

4. Witik, R. A., Payet, J., Michaud, V., Ludwig, C., and Manson, J.-A. E. 2011. Assessing the life cycle costs and environmental performance of lightweight materials in automobile applications. Composites: Part A 42(11): 1694-1709.

5. Hodkinson, R., and Fenton, J. 2000. Lightweight construction materials and techniques. Lightweight Electric/Hybrid Vehicle Design 44(3): 173-198.

6. Davies, G. 2003. Future trends in automotive body materials. Materials for $\mathrm{Au}$ tomobile Bodies: 547-396.

7. Ageorges, C., Ye, L., and Hou, M. 2001. Advances in fusion bonding techniques for joining thermoplastic matrix. Composites: Part A 32(6): 839-857.

8. Fiorini, M., Campana, G., Pagano, N., and Morelli, R. 2015. Comparison between joining technologies for polymeric films. $9^{\text {th }}$ CIRP Conference on Intelligent Computation in Manufacturing Engineering CIRP ICME '14. Procedia CIRP 33:

412-417.

9. Amancio-Filho, S. T., and dos Santos, J. F. 2009. Joining of polymers and polymer-metal hybrid structures: Recent developments and trends. Polymer Engineering and Science 49(8): 1461-1476.

10. Grewell, D., and Benatar, A. 2007. Welding of plastic: Fundamentals and new developments. International Polymer Processing 22(1): 43-60.

11. Levy, A., Le Corre, S., Chevaugeon, N., and Poitou, A. 2011. A level set based approach for the finite element simulation of a forming process involving multiphysics coupling: Ultrasonic welding of thermoplastic composites. European Journal of Mechanics A: Solids 30(4): 501-509.

12. Benatar, A., Eswaran, R. V., and Nayar, S. K. 1989. Ultrasonic welding of thermoplastics in the near-field. Polymer Engineering and Science 29(29): 1689-1698.

13. Benatar, A., and Cheng, Z. 1989. Ultrasonic welding of thermoplastics in the far-field. Polymer Engineering and Science 29(29): 1699-1704.

14. Schell, J. S. U., Guilleminot, J., Binetruy, C., and Krawczak, P. 2009. Computational and experimental analysis of fusion bonding in thermoplastic composites: Influence of process parameters. Journal of Materials Processing Technology 209(11): 5211-5219.

15. Srajbr, C., Tanasie, G., Dilger, K., and Bohm, S. 2011. Active thermography for quality assurance of joints in automobile manufacturing. Welding in the World 55(7-8): 90-97.

16. Khoy, Y., Chien, L.-H., Chang, B. C., and Liu, S.-J. 2000. Effects of the shape of the energy director on far-field ultrasonic 
welding of thermoplastics. Polymer Engineering and Science 40(1): 157-167.

17. Tolunay, M. N., Dawson, P. R., and Wang, K. K. 1983. Heating and bonding mechanisms in ultrasonic welding of thermoplastics. Polymer Engineering and Science 2(13): 726-733.

18. Stokes, V. K. 1988. Vibration welding of thermoplastics Part I: Phenomenology of the welding process. Polymer Engineering and Science 28(11): 718-727.

19. Van Wijk, H., Luiten, G. A., Van Eengen, P. G., and Nonhof, C. J. 1996. Process optimization of ultrasonic welding. Polymer Engineering and Science 36(9): 1165-1176.

20. Bates, P. J., MacDonald, J., Sidiropoulos, V., and Liang, H. 2001. Meltdown-time profiles of vibration welded polyamide 66 compounds. Society of Plastics Engineers $59^{\text {th }}$ Annual Technical Conference, pp. 1224-1228.

21. Fernandez Villegas, I. 2015. In situ monitoring of ultrasonic welding of thermoplastic composites through power and displacement data. Journal of Thermoplastic
Composite Materials 28(1): 66-85.

22. Fernandez Villegas, I. 2014.

Strength development versus process data in ultrasonic welding of thermoplastic composites with flat energy directors and its application to the definition of optimum processing parameters. Composites: Part A: Applied Science and Manufacturing 65(10): 27-37.

23. Bates, P. J., and MacDonald, J. 2005. Comparison of experimental and analytical vibration welding meltdown-time profiles for nylon 66 and polypropylene. Polymer Engineering and Science 45(6): 789-797.

24. Stokes, V. K. 1988. Vibration welding of thermoplastics. Part II: Analysis of the welding process. Polymer Engineering and Science 28(11): 728-739.

25. Zhi, Q., Tan, X., Lu, L., Chen, L., Li, J., and Liu, Z. 2017. Decomposition of ultrasonically welded carbon fiber/polyamide 66 and its effect on weld quality. Weld in the World 61(5): 1017-1028.

26. Zhi, Q., Tan, X., and Liu, Z. 2017. Effect of moisture on the ultrasonic welding of carbon-fiber-reinforced polyamide
66 composite. Welding Journal 96(6): 185-s to $192-$ s.

27. Nonhof, C. J., and Luiten, G. A. 1996. Estimates for process conditions during the ultrasonic welding of thermoplastics. Polymer Engineering and Science 36(9): 1177-1183.

QIAN ZHI, YU-HAO GAO, LEI LIU, and ZHONG-XIA LIU (liuzhongxia @zzu.edu.cn) are with the Key Lab of Materials Physics, School of Physics and Engineering, Zhengzhou University, Zhengzhou, Henan, China. PEICHUNG WANG is with the Manufacturing Systems Research Lab, General Motors Research and Development Center, Warren, Mich.

\title{
Welding Journal Now Publishing Direct Object Identifier (DOI) Numbers
}

\author{
Dear members of the welding research community,
}

Note that with this issue of the Welding Journal Research Supplement, we are including Direct Object Identifier (DOI) numbers with each of the papers published in print and online. (We have also backnumbered the papers published in the January and February 2018 issues.) A direct object identifier is a unique alphanumeric string assigned by a registration agency (we are using Crossref.org) to identify content and provide a persistent link to its location on the Internet. Our decision to begin assigning a DOI for each paper comes directly from a request by the research community.

As part of our obligation to Crossref.org, we are asked to provide DOI numbers, when available, in the references section of papers. So, if you have submitted a paper to the Welding Journal or are planning on submitting a paper, we ask that you update your references to include DOI numbers whenever possible.

Thank you.

Mary Ruth Johnsen, Publisher, Welding Journal 